\title{
Localization of the duodenal pacemaker and its role in the organization of duodenal myoelectric activity $^{1}$
}

\author{
JOHN HERMON-TAYLOR ${ }^{2}$ AND CHARLES F. CODE \\ From the Mayo Clinic and Mayo Foundation, Rochester, Minnesota, USA
}

SUMMARY In two series of conscious healthy dogs, a study of duodenal electric activity was made to locate the pacemaker or site of the greatest intrinsic frequency of the pacesetter potential. In three dogs, an annular myotomy of the duodenum about $1 \mathrm{~cm}$ proximal (orad) to the biliary ampulla caused a reduction in the frequency of the pacesetter potential distal (caudad) to the conduction block and demonstrated that the pacemaker was not in the region of the ampulla, as had been suggested previously. Annular myotomy of the duodenum at increasing intervals distal to the pylorus in a second series of eight dogs showed that the pacemaker was present in the proximal 5 to $6 \mathrm{~mm}$ of duodenum. The greater frequency of the pacemaker was found to maintain constant distal conduction of the pacesetter potential. Distal conduction of the pacesetter potential was shown on occasion to be associated with the distal propagation of action potentials along the duodenum.

Since the early observations of Alvarez and Mahoney (1922a and b), it has become established that a cyclically recurring rhythmic change in electric potential is propagated caudally in the longitudinal muscle layer of the small intestine of many species, including man. This has been termed the slow wave, basic electric rhythm, or pacesetter potential. According to current interpretation (Bortoff, 1965; Code, Szurszewski, Kelly, and Smith, 1968; Nelsen and Becker, 1968), the function of the pacesetter potential is to organize the motor activity of the small bowel and to define its maximal contractile frequency.

Records obtained from extracellular electrodes at different levels of intact small intestine have shown that the frequency of oscillation of the pacesetter potential is greatest in the duodenum and jejunum and decreases progressively toward the terminal ileum (Armstrong, Milton, and Smith, 1956; Daniel, Carlow, Wachter, Sutherland, and Bogoch, 1959; Bunker, Johnson, and

Received for publication 11 September 1970.

${ }^{1}$ This investigation was supported in part by research grant AM2015 from the National Institutes of Health, Public Health Service.

Recipient of a Medical Research Council travelling fellowship. Present address: The London Hospital, London E1.
Nelsen, 1967; Diamant and Bortoff, 1969a; Code and Szurszewski, unpublished data). Recordings from intracellular electrodes have demonstrated that fluctuation of the pacesetter potential is a property inherent in the cells of the longitudinal smooth-muscle layer (Daniel, Honour, and Bogoch, 1960; Bortoff, 1961 and 1965; Kobayashi, Nagai, and Prosser, 1966). Thus, the pacesetter potential can also be detected from segments of small intestine isolated in vitro or transplanted to an ectopic site in vivo (Puestow, 1932; Berkson, 1933; Daniel and Bogoch, 1959). In such isolated circumstances the frequency of the pacesetter potential is that intrinsic (natural) to the segment.

Except in the proximal (orad) duodenum and terminal ileum, the frequency in situ of the pacesetter potential at any level in intact small intestine is greater than its intrinsic or natural frequency (Diamant and Bortoff, 1969a). This is because the influence of the faster frequency of the pacesetter potential in the duodenum is propagated along the intestine, and is the basis for the concept of a 'duodenal pacemaker'. In the dog, the influence of the duodenal pacemaker may increase the frequency of the pacesetter potential (and therefore the maximal frequency of contrac- 
tion) as far as the ileum (Hasselbrack and Thomas, 1961 ; Diamant and Bortoff, 1969b).

Milton and Smith (1956) were the first to suggest that in dogs the pacemaker was present in the duodenal wall close to the entry of the bile duct. Bunker et al (1967) transected the duodenal bulb proximal (orad) to the biliary ampulla in two dogs and noted a reduction in the frequency of the pacesetter potential distal (caudad) to the cut. Because this reduction was small (from $17 \cdot 4$ to 16.9 and from 17.3 to 16.7 cycles per minute), they concluded that their results supported the concept of an ampullary pacemaker.

Despite these observations, the portion of the duodenum possessing the greatest intrinsic frequency of the pacesetter potential has not been accurately identified. The purpose of this investigation was to localize this area and to study its influence on duodenal electric activity.

\section{Materials and Methods}

In 12 conscious healthy dogs (10 to $18 \mathrm{~kg}$ ) recordings were obtained of the electric activity of the smooth muscle of the duodenum and in some cases of the gastric antrum from surgically implanted electrodes.

\section{RECORDING APPARATUS}

Platinum electrodes, $0.5 \mathrm{~mm}$ in diameter, were mounted in Teflon disks. In the first series of four dogs, the size of the Teflon disk was $8 \mathrm{~mm}$. In the second series, the size was reduced to $5 \mathrm{~mm}$. Seven electrodes were used in each dog. Insulated copper wires led from the electrodes to a connector mounted in a Teflon cannula, which was implanted in the right flank of the dog at the end of the surgical procedure.

Records of the electric sequence at each electrode were obtained with a Brush 8-channel rectilinear penwriter using an AC-coupled input amplifier at a time constant of 1 second. An indifferent electrode was inserted subcutaneously in the hind limb at each recording session. The dogs were trained to stand quietly, partially supported by a canvas sling, during tests.

\section{EXPERIMENTAL DESIGN}

Two experimental designs were used, the first to determine whether the pacemaker was located in the region of the biliary ampulla, and the second to determine the site of maximal natural frequency of the pacesetter potential in the duodenal wall.

In each of a first series of four dogs, seven Teflon-mounted electrodes were sutured to the serosal surface of the gut (Fig. 1). The first

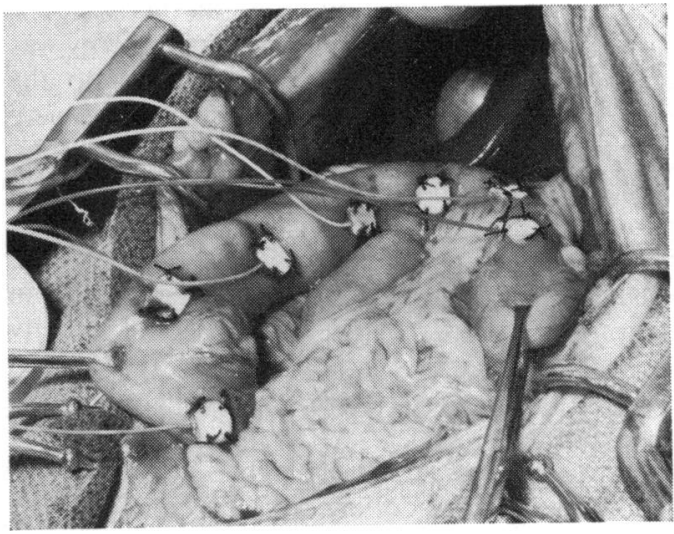

Fig. 1 Gastric antrum (on the right) and duodenum showing serosal electrodes in position. First series of dogs.

electrode was placed on the gastric antrum 1 to 2 $\mathrm{cm}$ from the pylorus, and the subsequent six electrodes were placed on the duodenum at intervals of 2 to $4 \mathrm{~cm}$. The position of the last electrode varied from 13 to $18 \mathrm{~cm}$ distal to the pylorus.

After recovery from operation, records of duodenal electric activity were made at intervals over a period of four months, both when the dogs had been fasted for 24 hours and after food.

A second operation was then performed on each dog to interrupt the continuity of the duodenal muscle. The duodenum was exposed through a right thoracotomy, dividing the diaphragm in the line of its fibres. The circumference of the duodenum was displayed at the site selected for myotomy by dissecting free the pancreas for about $1 \mathrm{~cm}$. The blood supply to the duodenum was preserved. An annular myotomy was performed, using coagulating diathermy, without dividing the mucosa. The duodenal muscle was sutured with catgut, and the wound was closed. The position of the biliary ampulla and

\begin{tabular}{lll}
\hline Dog & Ampulla & Myotomy \\
\hline 1 & $3 \cdot 7$ & $2 \cdot 8$ \\
2 & $4 \cdot 0$ & 3.0 \\
3 & $4 \cdot 2$ & $3 \cdot 2$ \\
4 & $4 \cdot 3$ & 6.0 and 13.0 \\
\hline
\end{tabular}

Table I Location (cm from pylorus) of biliary ampulla and annular myotomy in the duodenum of four dogs 
myotomy site in the four dogs in this series is shown in Table I. In three dogs, the myotomy was performed about $1 \mathrm{~cm}$ proximal (orad) to the biliary ampulla; in one dog, two myotomies were performed distal (caudad) to the biliary ampulla, one at the level of the entrance of the main pancreatic duct and the other $7 \mathrm{~cm}$ distally, where the head of the pancreas left its intimate relation with the duodenum. After recovery from operation, records of duodenal electric activity were obtained, at first daily and thereafter between one and three times a week for a further period of four months.

In a second series of eight dogs, annular myotomy of the duodenum in the manner described was carried out at the time of electrode implantation. In all dogs, the duodenum was exposed through a midline abdominal incision. One electrode was placed proximal to the myotomy, and the other six were placed in a series, between 0.5 and $1 \mathrm{~cm}$ apart, distal to the myotomy (Fig. 2). In one dog the myotomy was at the pylorus, in two dogs on the duodenum $5 \mathrm{~mm}$ from the pylorus, in three dogs between 6 and 9 $\mathrm{mm}$ from the pylorus, and in two dogs $24 \mathrm{~mm}$ from the pylorus. Identification of the pyloric ring at the time of operation was made by sight and feel. After recovery from operation, records of duodenal electric activity were obtained over a mean period of seven and a half weeks (range 1 to 16).

\section{ANALYSIS OF RECORDS}

The simultaneous frequency of the pacesetter potential at each electrode was determined by counting the number of cycles of pacesetter potential (to the nearest $0 \cdot 1$ of a cycle) over a period of one minute. The direction of conduction of the pacesetter potential was noted in all records.

\section{Results}

\section{FREQUENCY OF THE PACESETTER}

POTENTIAL

The mean frequencies of the duodenal pacesetter potential in the first series of four dogs in the four-month control period of observation before myotomy were $19 \cdot 6,18 \cdot 7,19 \cdot 7$, and 19.2 cycles per minute (cpm). In each dog, some day-to-day variation in frequency occurred, but at any one time the frequency detected was identical to all duodenal electrodes.

In three dogs, after annular myotomy approximately $1 \mathrm{~cm}$ proximal (orad) to the biliary ampulla, the frequency of the pacesetter potential distal (caudad) to the cut was always less than the

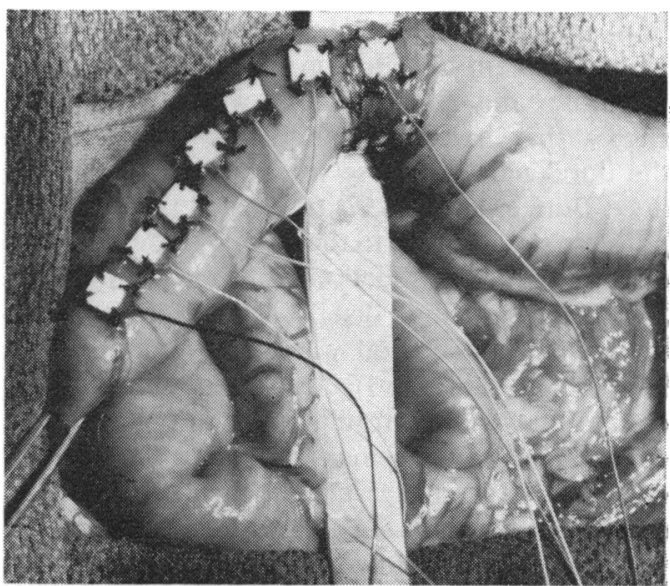

Fig. 2 Gastric antrum (on the right) and duodenum showing annular myotomy $9 \mathrm{~mm}$ distal to pylorus and position of serosal electrodes. Second series of dogs.

frequency in the duodenum proximal to the cut (mean difference 1.4, 3.2, and 2.9 cpm, respectively). The small reduction in the mean frequency of the pacesetter potential proximal to the cut $(0.3$ to 0.6 $\mathrm{cpm}$ ) that occurred after myotomy was not statistically significant. The reduction in frequency of the pacesetter potential distal to the myotomy was accompanied by an increase in its variability in all animals.

In the fourth dog of this series, myotomy distal to the biliary ampulla at the level of the main pancreatic duct caused a reduction in mean frequency of the pacesetter potential of $5.9 \mathrm{cpm}$ distal to the cut. As before, changes in the mean frequency in the proximal duodenum were not statistically significant. In this dog, a second myotomy of the duodenum $(7 \mathrm{~cm}$ distal to the first) did not cause further reduction in the mean frequency of pacesetter potential. In all four dogs, the effects of myotomy on the frequency of the potential were permanent over the subsequent four-month period of observation. These results indicate that the greatest intrinsic frequency of the pacesetter potential is not in the region of the biliary ampulla but is in a more proximal portion of the duodenum (Table II).

In the second series of dogs, myotomy on the pylorus had no detectable effect on the frequency of duodenal pacesetter potential. Myotomy $5 \mathrm{~mm}$ distal to the pylorus resulted in no significant difference $(P=0 \cdot 1)$ in the mean frequency of the pacesetter potential on either side of the cut. When the myotomy was placed 6 to $8 \mathrm{~mm}$ from 


\begin{tabular}{|c|c|c|c|c|c|c|c|c|c|}
\hline \multirow[t]{2}{*}{ Electrode Site } & \multirow{2}{*}{$\begin{array}{l}\text { Electrode } \\
\text { No. }\end{array}$} & \multicolumn{4}{|c|}{ Before Myotomy } & \multicolumn{4}{|c|}{ After Myotomy $y^{2}$} \\
\hline & & Dog 1 & Dog 2 & Dog 3 & $\operatorname{Dog} 4$ & $\operatorname{Dog} 1$ & Dog 2 & Dog 3 & $\operatorname{Dog} 4$ \\
\hline $\begin{array}{l}\text { Gastric antrum } \\
\text { Duodenum }\end{array}$ & $\begin{array}{l}1 \\
2\end{array}$ & $\begin{array}{r}7 \cdot 4 \pm 3 \cdot 6 \\
19 \cdot 6 \pm 0.7\end{array}$ & $\begin{array}{r}5 \cdot 7 \pm 0 \cdot 8 \\
18 \cdot 7 \pm 0 \cdot 8\end{array}$ & $\begin{array}{r}5.5 \pm 0.3 \\
19.7 \pm 0.6\end{array}$ & $\begin{array}{r}5 \cdot 4 \pm 1 \cdot 6 \\
19 \cdot 2 \pm 0 \cdot 4\end{array}$ & $\begin{array}{r}4.9 \pm 0.5 \\
19.0 \pm 0.4 \\
\text { Myotomy }\end{array}$ & $\begin{array}{r}5 \cdot 7 \pm 1 \cdot 2 \\
18 \cdot 4 \pm 0 \cdot 4 \\
\text { Myotomy }\end{array}$ & $\begin{array}{r}5 \cdot 5 \pm 0 \cdot 7 \\
19 \cdot 4 \pm 0 \cdot 5 \\
\text { Myotomy }\end{array}$ & $\begin{array}{r}5.6 \pm 1.0 \\
19.6 \pm 0.5\end{array}$ \\
\hline Biliary ampulla & a 3 & $19 \cdot 6 \pm 0 \cdot 7$ & $18.7 \pm 0.8$ & $19 \cdot 7 \pm 0 \cdot 6$ & $19 \cdot 2 \pm 0.4$ & $17.6 \pm 0.8$ & $15 \cdot 2 \pm 1 \cdot 3$ & $16.5 \pm 1.5$ & $\begin{array}{l}19.6 \pm 0.5 \\
\text { Myotomy }\end{array}$ \\
\hline $\begin{array}{l}\text { Duodenum } \\
\text { Duodenum }\end{array}$ & $\begin{array}{l}4 \\
5\end{array}$ & $\begin{array}{l}19 \cdot 6 \pm 0 \cdot 7 \\
19 \cdot 6 \pm 0 \cdot 7\end{array}$ & $\begin{array}{l}18 \cdot 7 \pm 0.8 \\
18 \cdot 7 \pm 0 \cdot 8\end{array}$ & $\begin{array}{l}19 \cdot 7 \pm 0.6 \\
19 \cdot 7 \pm 0.6\end{array}$ & $\begin{array}{l}19 \cdot 2 \pm 0.4 \\
19 \cdot 2 \pm 0.4\end{array}$ & $\begin{array}{l}17 \cdot 6 \pm 0.8 \\
17 \cdot 5 \pm 0.9\end{array}$ & $\begin{array}{l}15 \cdot 2 \pm 1 \cdot 3 \\
15 \cdot 2 \pm 1 \cdot 3\end{array}$ & $\begin{array}{l}16.5 \pm 1.5 \\
16.5 \pm 1.5\end{array}$ & $\begin{array}{l}13.7 \pm 1.6 \\
13.7 \pm 1.6 \\
\text { Myotomy }\end{array}$ \\
\hline $\begin{array}{l}\text { Duodenum } \\
\text { Duodenum }\end{array}$ & $\begin{array}{l}6 \\
7\end{array}$ & $\begin{array}{l}19 \cdot 6 \pm 0.7 \\
19 \cdot 6 \pm 0.7\end{array}$ & $\begin{array}{l}18.7 \pm 0.8 \\
18.7 \pm 0.8\end{array}$ & $\begin{array}{l}19 \cdot 7 \pm 0.6 \\
19 \cdot 7 \pm 0.6\end{array}$ & $\begin{array}{l}19 \cdot 2 \pm 0 \cdot 4 \\
19 \cdot 2 \pm 0 \cdot 4\end{array}$ & $\begin{array}{l}17.5 \pm 0.9 \\
17.5 \pm 0.9\end{array}$ & $\begin{array}{l}15 \cdot 2 \pm 1 \cdot 3 \\
15 \cdot 2 \pm 1 \cdot 3\end{array}$ & $\begin{array}{l}16.5 \pm 1.5 \\
16.5 \pm 1.5\end{array}$ & $\begin{array}{l}13.8 \pm 0.6 \\
13.8 \pm 0.6\end{array}$ \\
\hline
\end{tabular}

Table II Frequency of pacesetter potential in four conscious dogs before and after annular myotomy of the duodenum

${ }^{1}$ Mean \pm 1 SD (multiple observations over 4 months).

'Myotomy performed between electrodes as indicated

\begin{tabular}{|c|c|c|c|c|c|c|c|c|c|}
\hline \multirow[t]{3}{*}{ Dog } & \multirow{3}{*}{$\begin{array}{l}\text { Level of Myotomy } \\
\text { (mm from pylorus) }\end{array}$} & \multicolumn{7}{|c|}{ Frequency of Pacesetter Potential (cpm) at Electrode Number } & \multirow{2}{*}{$\begin{array}{l}\text { Weeks of } \\
\text { Observation }\end{array}$} \\
\hline & & 1 & 2 & 3 & 4 & 5 & 6 & 7 & \\
\hline & & $\begin{array}{l}\text { Proximal to } \\
\text { Myotomy }\end{array}$ & \multicolumn{7}{|c|}{ Distal to Myotomy } \\
\hline $\begin{array}{r}5 \\
6 \\
7 \\
8 \\
9 \\
10 \\
11 \\
12\end{array}$ & $\begin{array}{l}0 \\
5 \\
5 \\
6-8^{2} \\
6-8^{2} \\
9^{2} \\
24^{2} \\
24^{2}\end{array}$ & $\begin{array}{r}4.6 \pm 0.5 \\
16.9 \pm 1.8 \\
16.7 \pm 0.7 \\
18.1 \pm 0.5 \\
18.7 \pm 0.4 \\
19.0 \pm 0.9 \\
18.4 \pm 0.3 \\
18.3 \pm 0.4\end{array}$ & $\begin{array}{l}19.0 \pm 0.7 \\
17.5 \pm 2.2 \\
16.6 \pm 1.3 \\
17.2 \pm 1.5 \\
17.9 \pm 0.9 \\
17.3 \pm 1.5 \\
16.5 \pm 0.8 \\
13.4 \pm 0.6\end{array}$ & $\begin{array}{l}19.0 \pm 0.7 \\
17.5 \pm 2.2 \\
16.6 \pm 1.4 \\
17.2 \pm 1.5 \\
17.9 \pm 0.9 \\
17.3 \pm 1.5 \\
16.5 \pm 0.8 \\
13.4 \pm 0.6\end{array}$ & $\begin{array}{l}19.0 \pm 0.7 \\
17.5 \pm 2.2 \\
16.6 \pm 1.4 \\
17.2 \pm 1.5 \\
17.9 \pm 0.9 \\
17.3 \pm 1.5 \\
16.5 \pm 0.8 \\
13.4 \pm 0.6\end{array}$ & $\begin{array}{l}19.0 \pm 0.7 \\
17.5 \pm 2.2 \\
16.6 \pm 1.4 \\
17.2 \pm 1.5 \\
17.9 \pm 0.9 \\
17.3 \pm 1.5 \\
16.5 \pm 0.8 \\
13.4 \pm 0.6\end{array}$ & $\begin{array}{l}19.0 \pm 0.7 \\
17.5 \pm 2.2 \\
16.6 \pm 1.5 \\
17.2 \pm 1.5 \\
17.9 \pm 0.9 \\
17.3 \pm 1.5 \\
16.5 \pm 0.8 \\
13.4 \pm 0.6\end{array}$ & $\begin{array}{c}19.0 \pm 0.7 \\
17.5 \pm 2.2 \\
16.7 \pm 1.5 \\
17.2 \pm 1.5 \\
17.9 \pm 0.9 \\
17.3 \pm 1.5 \\
\pm \\
13.4 \pm 0.6\end{array}$ & $\begin{array}{r}2 \\
8 \\
1 \\
8 \\
8 \\
16 \\
9 \\
8\end{array}$ \\
\hline
\end{tabular}

Table III Effect of annular myotomy of duodenum at increasing intervals from pylorus on frequency of duodenal pacesetter potential ${ }^{1}$

${ }^{1}$ Means \pm 1 SD (multiple observations in conscious dogs).

'P $<0.01$.

the pylorus, the results were very similar and so were grouped together. In these instances, there was a small $(0.8$ and $0.9 \mathrm{cpm})$ but significant $(P<0.01)$ reduction in mean frequency of the pacesetter potential on the distal side of the cut. A reduction $(1.7 \mathrm{cpm})$ in mean frequency of pacesetter potential was noted in the duodenum beyond a myotomy $9 \mathrm{~mm}$ distal to the pylorus; in the two dogs with myotomy $24 \mathrm{~mm}$ from the pylorus, the mean reductions were 1.9 and 4.9 cpm, respectively. In every dog with a duodenal myotomy, the frequency of the pacesetter potential was more variable distal to the cut than proximal to it, and, as before, the effects were permanent within the limits of the period of observation.

These results indicate that the duodenal pacemaker, or site of greatest intrinsic frequency of the pacesetter potential, is limited to the first 5 or 6 $\mathrm{mm}$ of duodenum distal to the pylorus (Table III).

After conduction of the pacesetter potential in the small intestine has been blocked by complete transection of the bowel or by annular myotomy as in these studies, the frequency of the potential immediately distal to the cut is the intrinsic or natural frequency of this segment of bowel, as has

\begin{tabular}{rll}
\hline Dog & $\begin{array}{l}\text { Position of Myotomy } \\
\text { (cm from pylorus) }\end{array}$ & $\begin{array}{l}\text { Reduction in Pacesetter Potential } \\
\text { Frequency (cpm) }\end{array}$ \\
\hline 5 & 0 & 0 \\
6 & 0.5 & 0 \\
7 & 0.5 & 0 \\
8 & $0.6-0.8$ & 0.9 \\
9 & $0.6-0.8$ & 0.8 \\
10 & 0.9 & 1.7 \\
11 & 2.4 & 1.9 \\
12 & 2.4 & 4.9 \\
1 & 2.8 & 1.4 \\
2 & 3.0 & 3.2 \\
3 & 3.2 & 2.9 \\
4 & 6.0 & 5.9 \\
\hline
\end{tabular}

Table IV Gradient of intrinsic frequency of pacesetter potential in the proximal duodenum of dogs 
been emphasized by Diamant and Bortoff (1969b). Data on both groups of dogs indicated in general that, within about the first 5 to $6 \mathrm{~cm}$ of duodenum, the greater the distance of myotomy from the pylorus, the greater the reduction in frequency distal to the cut (Table IV). A steep gradient, therefore, may be expected in the intrinsic frequency of the pacesetter potential in the proximal duodenum, a decrease from about 18 or $19 \mathrm{cpm}$ to 13 or $14 \mathrm{cpm}$ over the first 5 to $6 \mathrm{~cm}$ or less.

DIRECTION OF CONDUCTION OF

PACESETTER POTENTIAL

In the first series of four dogs, in which the electric activity of the intact duodenum was studied on multiple occasions over a period of four months, distal conduction of the pacesetter potential was always observed. The pacesetter potential was first detected by the most proximal duodenal electrode and thereafter at each electrode in turn in an orderly sequence (Fig. 3). The peak of the pacesetter potential was positive, except at the most proximal duodenal electrode where it varied in polarity and voltage.

Annular myotomy of the duodenum at about $1 \mathrm{~cm}$ proximal to the biliary ampulla permanently abolished the constancy of distal conduction of the pacesetter potential in the duodenum distal to the cut. The reduction in frequency of the pace-

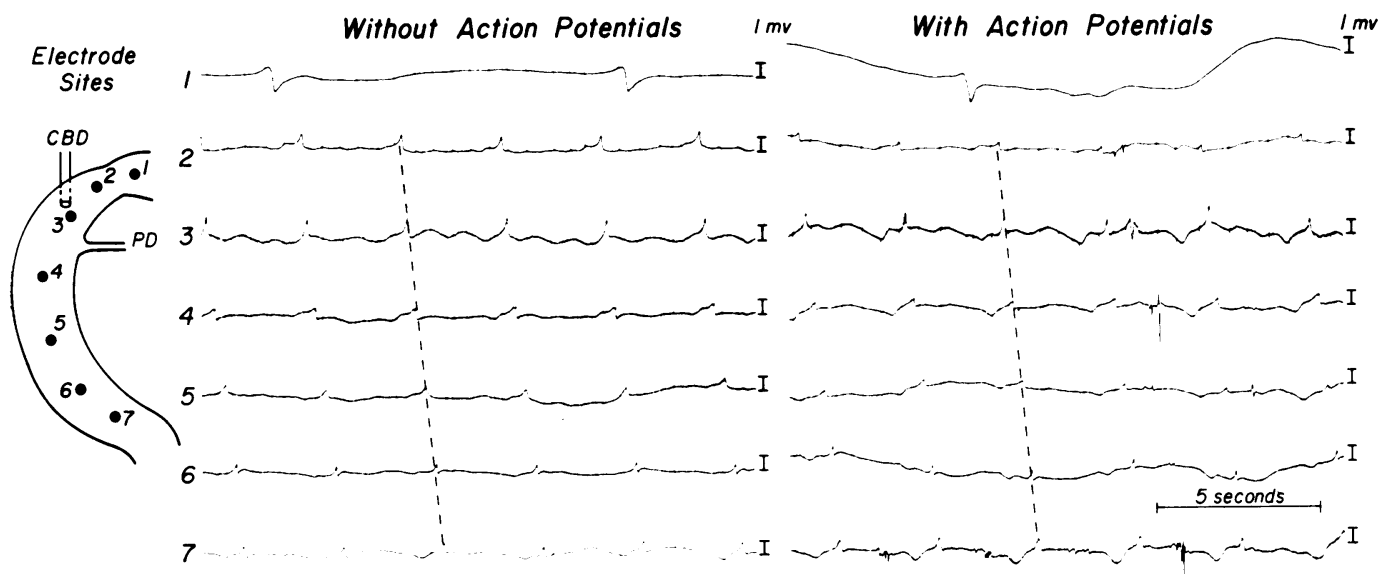

Fig. 3. Conduction of pacesetter potential in intact duodenum of a conscious dog with and without action potentials.
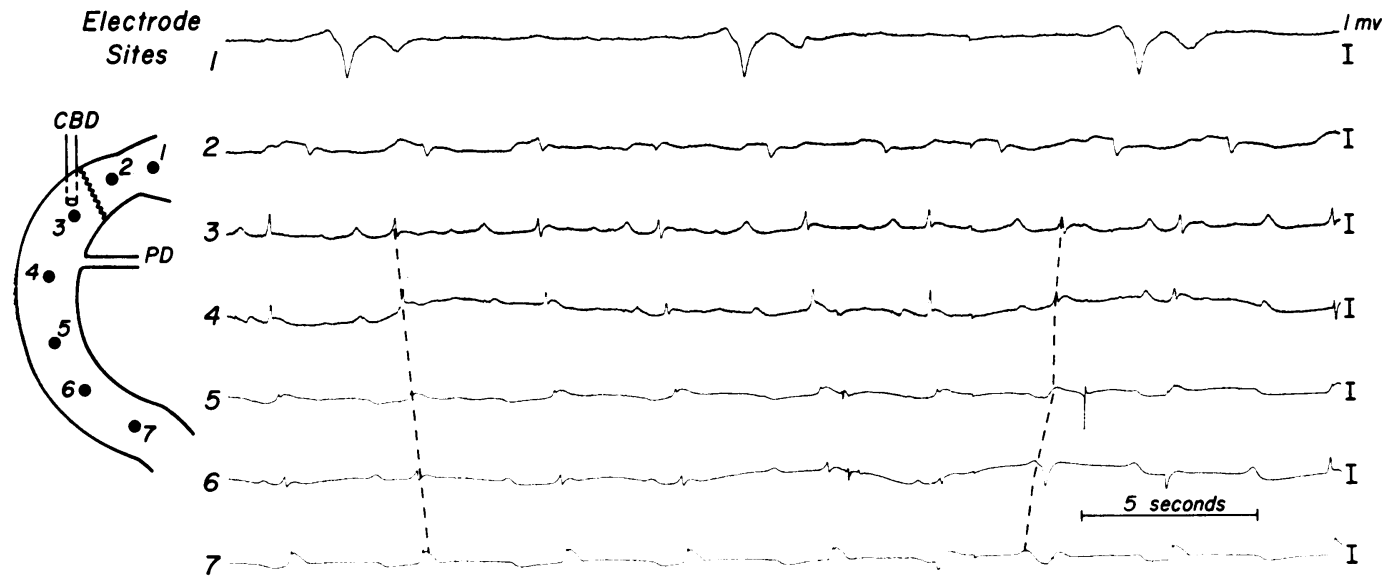

Fig. 4. Conduction of pacesetter potential in duodenum after annular myotomy $1 \mathrm{~cm}$ proximal to biliary ampulla. 


\section{Electrode Sites}
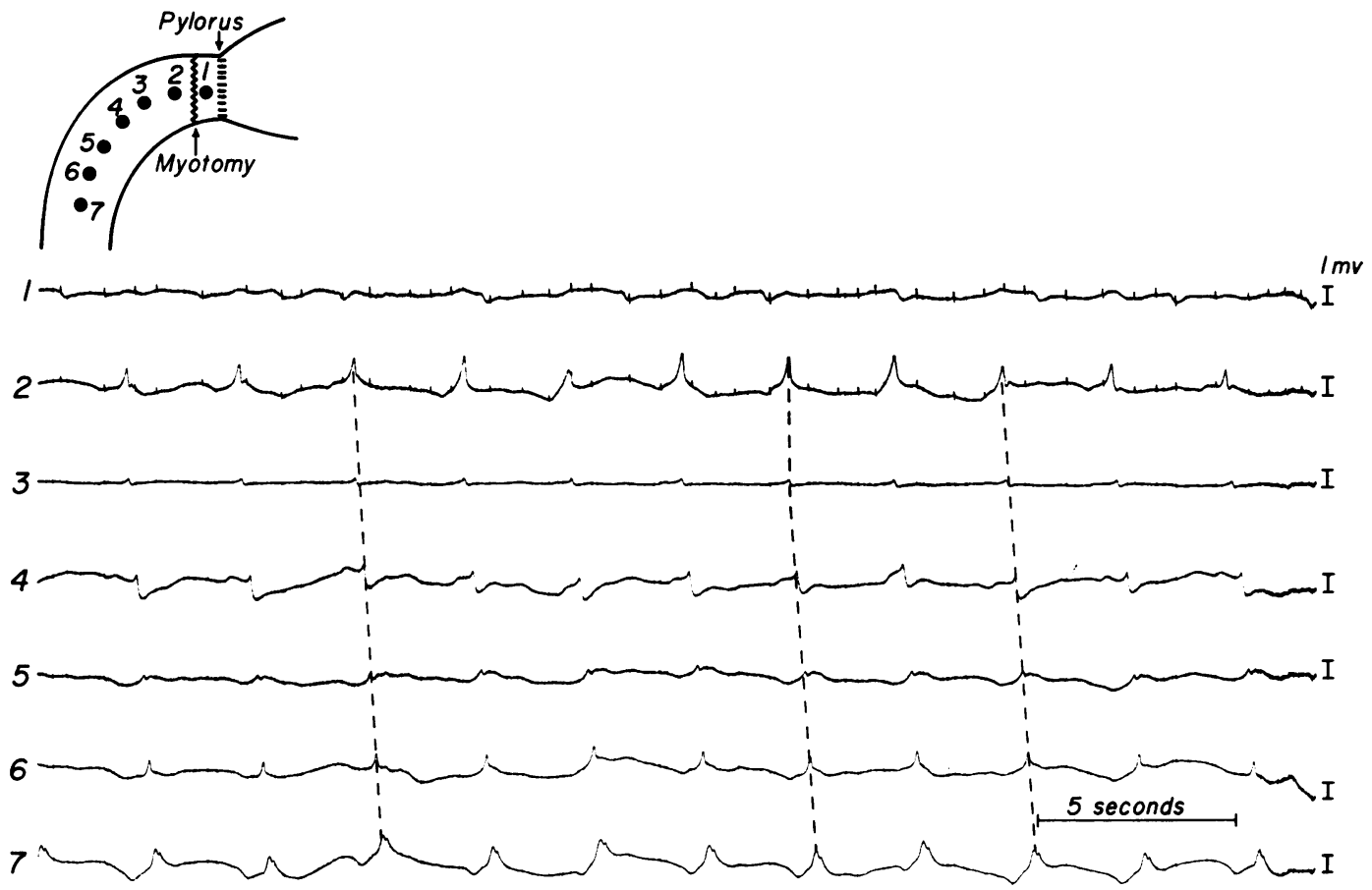

Fig. 5.

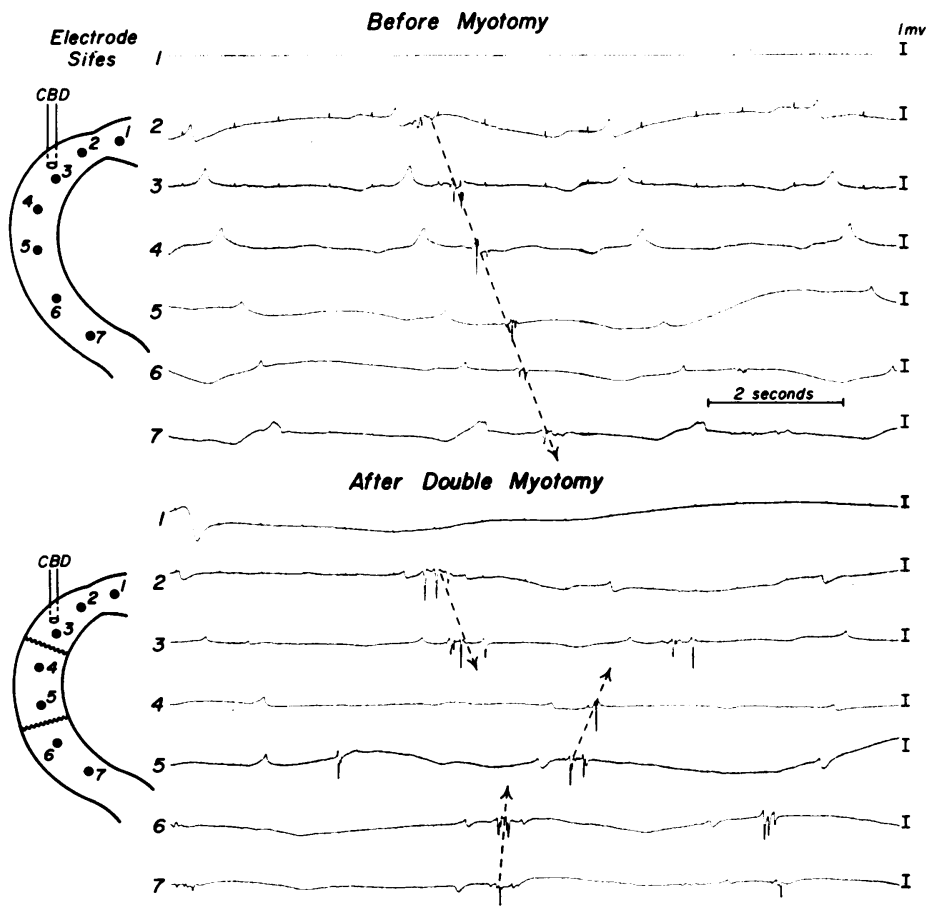

Fig. 5. Conduction and frequency of pacesetter potential after annular myotomy $5 \mathrm{~mm}$ distal to pylorus.

Fig. 6. Coordination of action potentials by conduction sequence of pacesetter potential in intact duodenum and the disorganization after dual annular myotomy. 
setter potential was associated with a varied direction of conduction (Fig. 4); in these circumstances, polarity was frequently reversed. This variability of origin and conduction of the pacesetter potential was confirmed by connecting individual electrodes as pairs and recording in a bipolar fashion. The loss of constant distal conduction was permanent over the subsequent four-month period of observation.

By contrast, when myotomy was performed 5 $\mathrm{mm}$ beyond the pylorus and no significant reduction in frequency noted, the constancy of distal conduction of the pacesetter potential was preserved, although, of course, the potential was not conducted across the cut (Fig. 5). An interpretation compatible with these findings would be that the pacemaker maintains the frequency and direction of conduction of the pacesetter potential in the duodenum and that myotomy $5 \mathrm{~mm}$ from the pylorus leaves tissue with pacemaker capability on the distal side of the cut.

COORDINATION OF ACTION POTENTIALS BY PACESETTER POTENTIAL SEQUENCE

In the four dogs studied both before and after myotomy, the occurrence of action potentials on the pacesetter potential was usually random, indicating irregular or non-rhythmic segmental contractions. On occasion, action potentials were noted at the same phase of a pacesetter potential cycle as it reached each duodenal electrode. When this occurred in the intact duodenum, the orderly distal conduction of the pacesetter potential produced a corresponding distal propagation of action potentials (Fig. 6). The mechanical correlate of this would be a peristaltic sweep along the duodenum, the velocity of which would be the same as the velocity of conduction of the pacesetter potential. Such orderly distal propagation of action potentials was not seen after myotomy because the myotomy had interrupted the propagation sequence of the pacesetter potential (Fig. 6).

Despite the disruption of organized duodenal electric activity by myotomy, there were no manifestations of a digestive disorder in any of the dogs, and preoperative body weights were rapidly regained and maintained.

\section{Discussion}

The frequency of the duodenal pacesetter potential of 18.7 to $19.7 \mathrm{cpm}$ in this study agrees with the findings of others where repeated observations were made in conscious dogs with the duodenum in its normal position (Bunker et al,
1967). This frequency approximates to that of rhythmic contractions of the exteriorized canine duodenum reported by Douglas (1948). We have shown that, when the pacesetter potential is conducted normally in the intact duodenum, its frequency is identical at multiple sites along the duodenum and that this is due to the presence of a pacemaker located in the wall of the first 5 or 6 $\mathrm{mm}$. This is the site of greatest intrinsic frequency of the pacesetter potential. Beyond this area, over a segment of duodenum the length of which is variable but about 5 to $6 \mathrm{~cm}$ long, a steep gradient in the intrinsic frequency of the pacesetter potential is present (revealed by blocking conduction in the muscle wall).

The more rapid frequency of the duodenal pacemaker ensures that under normal conditions the pacesetter potential is propagated in a distal direction from the pacemaker site over the rest of the duodenum. Such distal propagation can organize action potentials (motor activity) into a peristaltic sweep along the duodenum. Separation from the pacemaker exposes the slower more variable intrinsic frequency of the pacesetter potential in the rest of the duodenum; the site of origin and the direction of conduction of the pacesetter potential then become inconstant. These findings are in keeping with the concept that longitudinal intestinal smooth muscle behaves electrically much as a series of loosely coupled relaxation oscillators with successively decreasing intrinsic frequencies (Nelsen and Becker, 1968; Diamant and Bortoff, 1969a).

In the normal duodenum, retrograde propagation of the pacesetter potential and associated action potentials, which would be the electric counterpart of antiperistalsis, was not observed. The constancy of distal propagation of the pacesetter potential in the normal duodenum makes it difficult to conceive how antiperistalsis could occur unless conduction of the potential were disrupted.

The localization of the pacemaker to the first 5 or $6 \mathrm{~mm}$ of duodenum differs from the suggestion of Milton and Smith (1956) that a pacemaker is present in the region of the biliary ampulla. These authors based their proposal on experiments in anaesthetized dogs with exteriorized duodenal loops using cross clamping, cooling, cutting, or infiltration with procaine to block conduction of the pacesetter potential. The reason our findings differ is not certain, but it is probable that the greater precision of annular myotomy as a means of blocking conduction and the ability to make repeated observations in unanaesthetized healthy animals over a period of months provide for greater accuracy in defining the site of the 
maximal intrinsic frequency of the pacesetter potential.

The authors would like to express their gratitude for the technical assistance of Jerry C. Miller.

\section{References}

Alvarez, W. C., and Mahoney, L. J. (1922a). Action currents in stomach and intestine. Amer. J. Physiol., 58, 476-493.

Alvarez, W. C., and Mahoney, L. J. (1922b). The myogenic nature of the rhythmic contractions of the intestine. Amer. J. Physiol., 59, 421-430.

Armstrong, H. I. O., Milton, G W., and Smith, A. W. M. (1956) Electropotential changes of the small intestine. J. Physiol. (Lond.), 131, 147-153.

Berkson, J. (1933). Electromyographic studies of the gastrointestinal tract. III. Observations on excised intestine. Amer. J. Physiol., 104, 62-66.

Bortoff, A. (1961). Slow potential variations of small intestine. Amer. J. Physiol., 201, 203-208.

Bortoff, A. (1965). Electrical transmission of slow waves from longitudinal to circular intestinal muscle. Amer. J. Physiol. 209, 1254-1260.

Bunker, C. E., Johnson, L. P., and Nelsen, T. S. (1967). Chronic in-situ studies of the electrical activity of the small intestine. Arch. Surg., 95, 259-268.

Code, C. F., Szurszewski, J. H., Kelly, K. A., and Smith, I. B. (1968). A concept of control of gastrointestinal motility. In Handbook of Physiology: A Critical Comprehensive Presentation of Physiological Knowledge and Concepts.
Section 6: Alimentary Canal, edited by C. F. Code, vol. 5, pp. 2881-2896. American Physiological Society, Washington, $\mathrm{DC}$.

Daniel, E. E., and Bogoch, A. (1959). Mechanical and electrical activity of ileal segments isolated for uretero-ileal anastomosis. Canad. med. Ass. J., 80, 95-102.

Daniel, E. E., Carlow, D. R., Wachter, B. T., Sutherland, W. H., and Bogoch, A. (1959). Electrical activity of the small intestine. Gastroenterology, 37, 268-281.

Daniel, E. E., Honour, A. J., and Bogoch, A. (1960). Electrical activity of the longitudinal muscle of dog small intestine studied in vivo using microelectrodes. Amer. J. Physiol., 198 113-118.

Diamant, N. E., and Bortoff, A. (1969a). Nature of the intestinal slow-wave frequency gradient. Amer. J. Physiol., 216, 301-307.

Diamant, N. E., and Bortoff, A. (1969b). Effects of transection on the intestinal slow-wave frequency gradient. Amer. J. Physiol., 216, 734-743.

Douglas, D. M. (1948). The activity of the duodenum. J. Physiol. (Lond.), 107, 472-478.

Hasselbrack, R., and Thomas, J. E. (1961). Control of intestinal rhythmic contractions by a duodenal pacemaker. Amer. J. Physiol., 201, 955-960.

Kobayashi, M., Nagai, T., and Prosser, C. L. (1966). Electrical interaction between muscle layers of cat intestine. Amer. J. Physiol., 211, 1281-1291.

Milton, G. W., and Smith, A. W. M. (1956). The pacemaking area of the duodenum. J. Physiol. (Lond.), 132, 100-114.

Nelsen, T. S., and Becker, J. C. (1968). Simulation of the electrical and mechanical gradient of the small intestine. Amer. J. Physiol., 214, 749-757.

Puestow, C. B. (1932). The activity of isolated intestinal segments. Arch. Surg., 24, 565-573. 